\title{
The Influence of Immersive Environments on the Empathy Construct about Schizophrenia ${ }^{\dagger}$
}

\author{
Paulo Veloso Gomes ${ }^{1, *}$, António Marques ${ }^{1}$, Javier Pereira ${ }^{2}$ and João Donga ${ }^{1,3}$ \\ 1 LabRP, Laboratório de Reabilitação Psicossocial, Escola Superior de Saúde do Politécnico do Porto, 4200- \\ 072 Porto, Portugal \\ 2 CITIC-Research Center of Information and Communication Technologies, University of A Coruña, 15071 A \\ Coruña, Spain \\ 3 Escola Superior de Media Artes e Design do Politécnico do Porto, 4480-876 Vila do Conde, Portugal \\ * Correspondence: pvg@ess.ipp.pt; Tel.: +351-222-061-000 \\ † Presented at the 2nd XoveTIC Conference, A Coruña, Spain, 5-6 September 2019.
}

Published: 22 July 2019

\begin{abstract}
This work explores the potential of the use of interactive and immersive technologies to create impactful experiences that generate emotions, contributing to the process of activation or somatic excitation that triggers links that strengthen cognitive functions. It is intended to demonstrate to what extent the use of immersive environments, by generating a strong emotional load, contribute in a more effective way to the empathy construct about Schizophrenia.
\end{abstract}

Keywords: Mental Health and Welfare Literacy; schizophrenia; empathy; immersive environments; virtual reality; augmented reality; 360 Video

\section{Introduction}

Mental illness has an associated stigma from which there are serious consequences. This stigma, besides being a factor of social exclusion, can also negatively influence the provision of health care through inhibition of the search for medical care, the lack of motivation to adhere to the treatments applied and making difficult the information acquisition process essential for the promotion of health literacy. Consequently, stigma leads to increased associated mortality through factors such as treatment abandonment or suicide [1].

Literacy in Mental Health is essential to improve understanding and consequently acceptance of mental illness, contributing to overcoming prejudices and combating the stigma that leads to social exclusion [2].

Factual knowledge alone is not enough for there to be an effective understanding capable of generating empathy and attitudes. Emotions trigger the attention functions that are essential for the cognitive functions of perceptual, symbolic, and logical processing, help to memorize, facilitate, and clarify the perception of things, and empower executive functions for problem solving [3].

This paper describes the process of designing, developing and testing the multidimensional artifact "e-EMotion-Capsule" that exploits immersiveness to generate emotions through the creation of impacting environments.

The physical or emotional sensations felt by the individual generate emotions in order to create empathy and trigger feelings that promote actions.

\section{Objectives}

The objective of this work is to develop an innovative intervention methodology that, through the generation of impactful experiences, allows the use of emotion as a catalyst in the transmission of applied knowledge to the promotion of Literacy in Mental Health and Welfare. 
1. Design a model for the construction of a technological artefact that uses interactive and immersive technologies to generate impactful experiences.

2. Compare the impact caused by experiences that resort to different immersive concepts, virtual reality, 360 video and mixed environment (real scenarios and augmented reality).

\section{Materials and Methods}

A comparative study was designed to analyze and compare the impact of three immersive environments that reproduce episodes of the life of a person with schizophrenia. The study will be applied to a group of students who will be future health professionals and who may in future integrate mental health teams. The first immersive environment uses virtual reality scenarios (AIrv), the second uses a 360 video (AI360) and the third uses a mixed environment (AIrm) using real scenarios and augmented reality (Figure 1).

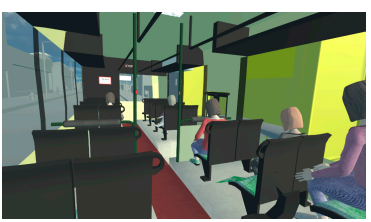

(a)

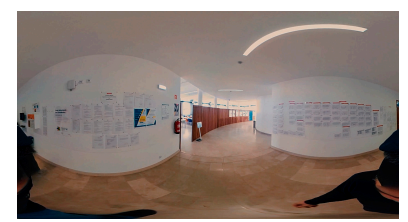

(b)

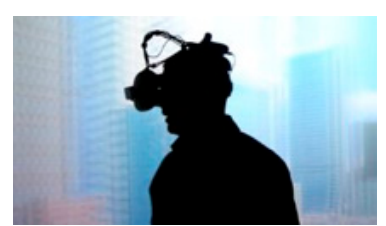

(c)

Figure 1. Representation of immersive environments: (a) AIrv-virtual reality; (b) AI360-360 vídeo; (c) AIrm - real scenarios/augmented reality.

After the observer is exposed to the target, the respective intrapersonal consequences are measured through the responses that occur in the observer by exposure. This measurement considers three dimensions, cognitive (interpretation), affective (empathy) and motivational (attitudes) that guide the behavioral responses.

In order to carry out the measurement, self-report evaluation instruments and psychophysiological measures are applied to analyze impact. The immersive environments differ in several factors that influence the lived experience, the type of interactivity possible to experience, the type of narrative and the scenarios used.

In the first phase, the work uses the Research-Action Methodology to design a model for the construction of the technological artefact, prepare the construction of the prototype and the tests to be implemented, identify the relevant indicators and prepare its application.

The second phase applies the developed model to specific cases, using specific Focus Groups.

The third phase focuses on evaluation of the impact of intervention and results discussion.

The physical or emotional sensations felt by the individual generate emotions, and the emotions trigger feelings that promote actions [4].

Since empathy is an important factor for positive human interaction, exposure to immersive environments awakens sensory experiences that are determinant for cognitive transmission.

\section{Discussion/Conclusions}

The learning process implies the interdependence of cognitive, emotional and behavioral responses involved in a social context [5].

It is intended to determine how the exposure to each of the three immersive environments contributes to increase the degree of empathy, knowledge and attitudes towards a person with schizophrenia.

The three environments under study are compared considering two dimensions, the environmental dimension and the impact dimension (Table 1).

The dimension "environment" focuses on the intrinsic characteristics of each of the immersive environments, considering the interactivity, immersiveness and realism of each environment. The "impact" dimension compares the result created by the exposure, considering the cognitive aspects, the empathy generated and the propensity to take attitudes. 
Table 1. Comparison of study dimensions.

\begin{tabular}{cccc}
\hline Dimension/Scale & AIrv & AI360 & AIrm \\
\hline ENVIRONMENT & & & \\
Interactivity & $-/+1$ & $-/+1$ & $-/+1$ \\
Immersion & $-/+1$ & $-/+1$ & $-/+1$ \\
Realism & $-/+1$ & $-/+1$ & $-/+1$ \\
Narrative type & $-/+1$ & $-/+1$ & $-/+1$ \\
IMPACT & & & \\
Cognitiveness & $-/+1$ & $-/+1$ & $-/+1$ \\
Empathy & $-/+1$ & $-/+1$ & $-/+1$ \\
Attitudes & $-/+1$ & $-/+1$ & $-/+1$ \\
\hline
\end{tabular}

${ }^{1}$ The scale will be defined according to the characteristics of the dimension under study.

It is important to determine the influence that each type of immersivity exerts on the observer in each of the considered dimensions, affective cognitive and motivational. Analyze if one of the environments stands out in one or more dimensions, so that it can determine which is the most appropriate for each specific type of intervention.

Author Contributions: Conceptualization, P.V.G.; methodology, P.V.G. and A.M.; validation, P.V.G. and J.D.; investigation, P.V.G.; writing-original draft preparation, P.V.G.; writing-review and editing, P.V.G.; visualization, P.V.G. and J.D.; supervision, A.M. and J.P.; project administration, P.V.G.

Funding: This research received no external funding.

Acknowledgments: This research was carried out and used the equipment of the Psychosocial Rehabilitation Laboratory (LabRp) of the Research Center in Rehabilitation of the School of Allied Health Technologies, Polytechnic Institute of Porto.

Conflicts of Interest: The authors declare no conflict of interest.

\section{References}

1. Vigo, D.; Thornicroft, G.; Atun, R. Estimating the true global burden of mental illness. Lancet Psychiatry 2016, 3, 171-178.

2. Capacitar as Pessoas e as comunidades para agir. Available online: http://fundacaovale.org/Paginas/NewsCapacitar-pessoas-e-alavancar-negocios-nas-comunidades-tambem-e-inovar.aspx (accessed on 2 June 2029).

3. da Fonseca, V. Importância das emoções na aprendizagem: uma abordagem neuropsicopedagógica. Rev. Psicopedag. 2016, 33, 365-384.

4. Virtual Reality Perspective-Taking Increases Cognitive Empathy for Specific Others. Available online: https://doi.org/10.1371/journal.pone.0202442 (accessed on 2 June 2029).

5. Feist, J.; Feist, G.J. Teorias da personalidade, 6th ed. São Paulo, 2008; ISBN: 978-85-7726-019-5.

(C) 2019 by the authors. Licensee MDPI, Basel, Switzerland. This article is an open access article distributed under the terms and conditions of the Creative Commons Attribution (CC BY) license (http://creativecommons.org/licenses/by/4.0/). 